\title{
The dilemma of newspaper cartoonists: perspectives from Nigerian practitioners
}

\author{
Semiu Bello ${ }^{*}$, Biodun Aleshinloye ${ }^{2}$ \\ ${ }^{1}$ Department of Mass Communication, Kwara State University, Malete, Nigeria \\ ${ }^{2}$ Department of Mass Communication, Olabisi Onabanjo University, Ago Iwoye, Nigeria \\ Corresponding author: semiuolabello@gmail.com
}

\begin{abstract}
Article History
Received: 10/08/2021

Revised: $10 / 11 / 2021$

Accepted: $11 / 11 / 2021$

Published: $31 / 12 / 2021$
\end{abstract}

\begin{abstract}
Cartooning in journalism practice is, by nature and as demonstrated in many parts of the world, an intelligent journalistic endeavor undertaken by cartoonists or cartoon journalists to put those in power to accountability and responsibility. It is a special genre of journalism profession to disseminate information graphically and illustratively to members of the public. Cartoonists strategically use cartoons and their journalistic drawings to portray social evils, corrupt practices, criticise policies and government programs, and actions of various corporate bodies, religious organisations, and individuals' misdemeanours in a satirical and comic form. In the course of performing these multifarious functions in society, cartoonists have been subjected to an array of challenges or have been made to go through various challenges and consequently thrown into dilemma. Investigating these challenges and how cartoon journalists have been able to cope in their trade and profession define the thesis of this study. Operationally, the study employs the in-depth interview research method to garner the perspectives of cartoon practitioners in Nigeria to determine the dimension of the challenges they encounter in their profession and what factors keep them in the profession. Among other challenges, this study finds that cartoon journalists encounter proprietor's influence, poor remuneration, lower estimation and respect by editors and other superior officers in media organisations, and threats, insecurity, and attacks from the politicians. Cartoon journalists, however, remain motivated and committed to their profession due to personal interest/passion and love for public interest.
\end{abstract}

Keywords: newspaper, political cartoon, cartoonists, journalism, Nigeria

\section{Introduction}

Cartooning in journalism practice is, by nature and as demonstrated in many parts of the world, an intelligent journalistic endeavor undertaken by cartoonists or cartoon journalists to put those in power to accountability and responsibility. It is a special genre of journalism profession to disseminate information graphically and illustratively to members of the public. Cartoonists strategically use cartoons and their journalistic drawings to portray social evils, corrupt practices, criticise policies and programmes 
of government, actions of various corporate bodies, religious organisations and individuals' misdemeanours in a satirical and comic form. Cartooning has been a very popular means of criticising political activities and politicians. Given the increased use of political cartoons, especially in Nigerian print media, and the fact that political cartoons rely on satire constructed in graphic or visual illustrations to express their meanings, political cartoons are viewed as a form of political satire (Townsend, McDonald, \& Esders., 2008). Through these verbal and visual devices, cartoonists construct meaningful and persuasive media messages reflecting current issues and scenarios that are related to social and political happenings in a society, thereby contributing significantly to political debates and commentary (Conners, 2005). Cartoons are pictorial representations that employ visual rhetoric to convey what happens in society. These messages are usually constructed to identify images of individuals, groups or events, and describe them according to how they refer to real-world events (Elkins, 2003).

As described by Townsend et al. (2008), satire and political cartoons are a form of satire that enables the public to interpret and understand political life in a particular society. Satire refers to the use of ingenious humour particularly irony, sarcasm and ridicule to criticise individuals' faults and behaviour (Townsend et al., 2008). It has also been described by Feldman (2005) as a playful distortion of reality. Originally, satire is a kind of literary art, especially poetry, meant for transforming society (Feldman, 2005). This traditional description of satire is quite realistic in our societies. It also applies to the cartoons whereby it is used in critical humour form to entertain, inform and reorient the audiences, and at the same time expose the vices of politicians and prominent personalities in societies. More specifically, the main concern of satire in Nigerian perspective is often geared towards abolishing corruption, duplicity, and rigidity of social, religious, and political institutions and their practices (Akande, 2002).

Newspaper cartoonists are often regarded as social and political reformers considering the nature, characteristic of newspaper cartoons and the functions they satirically perform through graphic illustrations (Robinson, 1981; Akande, 2002). The task a cartoonist performs is not an easy one considering the different visual devices that are put into play such as visual metaphor, humour, satire, exaggeration, and the context (Conners, 2005). Among these rhetorics, visual metaphor stands to be the most predominant device that Nigerian cartoonists harness to represent salient issues in society (Conners, 2005). Furthermore, it is noted that Nigerian political cartoons are described as "traditions" which refer to the conventions and narrative characteristics that reflect the indigenous Nigerian culture as part of African political cartoons. The tradition involves the use of legends, customs, rituals, creative use of traditional proverbs, vernacular language, and Pidgin English. This provides imaginative reflection and 
expression of the national culture and politics. Another feature of these cartoons is that they are dynamic rather than static and as such, they are easily mixed with the new tradition and the old in form of blending. In addition, its recurrent unique depictions make it politically revealing by portraying the real-life situation of political figures in a powerful presentation that really reflects the country's political arena.

Despite the important roles cartoonists perform in society and the values of their illustrations in exposing and correcting social ills, cartoonists in Nigerian society have been made to go through various challenges, which have thrown many of them into dilemma. Some of them have decided to leave the profession, while others still struggle to cope. But apparently, the female folk is completely missing on the field of cartoon journalism due to the challenges bewildering the practice of cartooning in Nigeria. Investigating the myriad of challenges confronting the practice of cartoon journalism in Nigeria is the thrust of this study. In doing this, the study sought the perspectives of cartoon journalists or cartoonists in Nigeria through in-depth interview method to determine the kind and nature of the challenges they have confronted over the years and the dilemma they have been thrown into and how they have managed to cope in their profession. Specifically, therefore, the study underpins the following questions to achieve the study's overall goal: (i) what forms of challenges are being confronted by cartoonists in cartoon journalism in Nigeria? (ii) what forms of challenges are being confronted by cartoonists in cartooning political and corruption issues? (iii) what factors motivate cartoonists in Nigeria in cartoon profession in Nigerian society despite various challenges being confronted?

Cartoons and cartoonists are important in our contemporary societies. They have been part of our political struggles and social constructions in Africa and the world at large. In the view of Olaniyan (2018), cartoons are journalistic endeavour that should be taking seriously considering its strategic approach in communicating issues. This is because, across Africa and the world, cartoonists make us laugh and ponder by showing us the daily events and crises in our societies. It is further averred that cartoonists reflect the idiocies or significance of politics while bolstering the resilience of grassroots people in the face of the exercise of power (Olaniyan, 2018). According to Jimoh (2010), Cartoons have played a major role in the political experience, particularly the democratisation process in Nigeria with specific reference to the military era. Even in African continent, cartoons are noted for their critical role in the cause of political liberation. For instance, Eko (2010) notes that African newspaper cartoons are critical journalistic texts that are among the most visible manifestations of post-cold war African political liberalisation. It is further argued that "since the early 1990s, cartoons have spearheaded the struggle for 
freedom of expression on the continent. One technique African cartoons have used to excoriate authoritarianism is to focus on political persecution of the media" (Eko, 2010, p. 69).

Globally, many governments, according to Lordan (2015) have historically employed various tools ranging from threats, smears and prison time to assaults and even murder to silence cartoonists because the overriding thoughts of political leaders is that cartoonists can be extremely influential. Hence, Jeff MacNelly, Pulitzer Prize-winning cartoonist, concludes that if political cartoonists could not draw, they probably would have become hired assassins considering the sharp words that underscore the provocative nature of a cartoonist's work. This makes cartoonists encounter many challenges in many countries of the world with no significant assistance or protection for carrying out their legitimate roles. Therefore, Charlie Hebdos, a cartoonist, avers that, around the world, cartoonists have millions of fans, but very few or no defenders! For instance, many cartoonists across African countries had gone through a tougher period with unwholesome experiences during colonialism, military rule, and even civil rule.

Specifically, in Nigeria, it was a period in the political life of the country when "the newspapers are awash with various images, cartoons and caricatures depicting the ills in the society. The themes range from corruption, political instability to electoral fraud” (Jimoh, 2010, p. i). Editorial cartoons, which are regarded as single panel graphics, are used to comment on political events and policy, and serve both to define the significant topics of political discourse and record them, thus creating a "snapshot" of the political climate in a given period (Jimoh, 2010). Cartoons are journalistic genres with constructed, ritualistic, interpretive texts (Eko, 2010) that involve the synoptic or sequential selection, ordering, structuring, positioning, segmenting, and communication of happenings (Hühn 2009). This is why cartoons are seen as an important medium in forming public opinion on salient political and social issues (Agberia, 1993; Adekanmbi, 1997; Everette, 1974; Vinson, 1967), as well as providing subtle framework for people to political processes of a country (DeSousa \& Medhurst, 1982). Eko (2010) concludes that cartoonists are social constructors and their constructivist activities are performed on slices of reality for purposes of political and social criticism, as well as ethical evaluation.

The implication of this is that cartoonists enjoy a good latitude of freedom to perform their duties yet, ethical consideration should be adhered too. This is because "one of the fundamental human rights guaranteed by the United Nations Universal Declaration of Human Rights is the right of freedom of opinion and expression. This right includes the right to impart information and ideas across frontiers. It goes without saying that freedom of expression includes freedom to disseminate information that will offend some people. This is the so-called right to offend. Cartoons are often instruments of deliberate 
graphic offence" (Eko \& Berkowitz 2009 cited in Eko, 2010, p. 70). Given the latitude of the freedom enjoyed by cartoonists to perform their duties and the inability of the government authorities to condone the "excesses of cartoonists" in exposing their ills, there appears to be an endless battle between the two sides. Eko (2010) lends credence to this fact that there are many African countries in which newspapers, journalists or cartoonists had major confrontations with their respective governments and/or judiciaries. Accordingly, "these 'confrontations' can result in journalists experiencing censorship (both overt and covert), kidnappings, beatings, imprisonment, forced exile, death threats, forced exile and even murder" (Eko, 2010, p. 70). This also resonates with the conclusion of Philip (2015) who asserts that political cartooning, which poses a lot of challenges to its authors and creators, reflect the society and historical period within which the cartoon is produced; and it is as an expression of corrupt social conditions, often tells untold stories and may challenge people to seek positive change. This, therefore, speaks to a major challenge that cartoonists face in the practice of their trade; the challenge of exposing the ills and unleashing attacks on the governments and politicians who occupy power and sit on the nation's treasure at the expense of the community good and the fight-back from the governments and their agents. This is what is described as 'confrontations' by Eko (2010) which "can result in journalists experiencing censorship (both overt and covert), kidnappings, beatings, imprisonment, forced exile, death threats, forced exile and even murder" (Eko, 2010, p. 70).

Furthermore, another challenge confronting the practice of cartooning in Nigeria is what can be regarded as industry-based challenge. This is being witnessed within the setup of different media organisations, from superior officers and proprietors in the industry. As noted by Eroje, a cartoonist at The Punch newspaper, editors are the bane of cartoon development in the country. Some editors consider cartoonists to be "less than reporters," showing them very little respect, with unwholesome remuneration. In some cases, newspapers do not have staff cartoonists, and prefer to depend on freelance labour. Sometimes, the cartoonist's creative effort is blatantly edited by fastidious editors who consider such interference a droit de seigneur. Such a demanding condition has effectively discouraged Nigerian females from taking up cartooning as a career. This is the view of Onyeka Adaobi, a former Vanguard female cartoonist-turned-textile designer. Adaobi sees cartooning in Nigeria as a tedious and difficult job that pays so little and demands so much. Women, accordingly, cannot keep up with the demands of Nigerian editors, who often ask for the impossible (Adaobi, 2000). Hence, Nigeria has not a single female cartoonist, and the only illustrator, Ronke Adesanya, has now left the field entirely for the males. In effect, cartoonists, based on the experiences of those interviewed were not appreciated within the purview 
of remuneration, conditions of service, and professional elevation and honour. Consequently, most cartoonists are compelled to do other things for sustenance; otherwise, they are distracted by their deprivations (Adaobi, 2000). The poor working and service conditions have, according to ObeEss, a cartoonist at The Guardian newspaper, forced many cartoonists out of the profession. The influence of the proprietors, according to Oloruntola, a cartoonist at The Guardian newspaper, is another major setback in the profession because he who pays the piper dictates the tune.

Cartoon journalism in newspapers or the press hinges on both the libertarian and social responsibility theories of the press. This is because by cartooning, journalists have the freedom to portray and disseminate various issues in society more effectively than written words. Specifically, however, the social responsibility theory has more bearing on this study than libertarian theory considering the fact that the use of cartoons by newspapers to satirise events, misdemeanours, and other social ills is in consonance with the postulations of social responsibility theory. As noted by to Hyun, Yang, Jung and Hong (2016). Hyun et. al. (2016) the social responsibility theory (SRT) argues that the press has a responsibility to the public. This theoretical approach is a result of broadcasting and media ethics. Early communication administrators such as Robert Hutchins (Head of the Commission on Freedom of the Press in the United States) expressed concern over communication ethics in libertarian media cultures. In other words, social responsibility theory gives the media some ethics and guide to curtail some excesses which was in vogue in the preceding theory of libertarian. This theory balances freedom with responsibilities which bring the media to stewardship account of the public with a duty to be vigilant on behalf of the citizens and fair to all. The social responsibility theory was saddled with not just factual reporting but investigative reporting to produce relevant and trustworthy news.

The media are also made under this theory to fulfil certain obligation to the public. McQuail (2010) summarizes the basic principles of social responsibility theory as follows: Media should accept and fulfill certain obligations to society, these obligations are mainly to be met by setting high or professional standards of informativeness, truth, accuracy, objectivity and balance. In accepting and applying these obligations, media should self-regulate within the framework of law and established institutions. The media should avoid offensive content triggering crime, violence, civil disorder, or harm to minority groups. The media as a whole should be pluralist and reflect the diversity of their society, giving access to various points of view and rights of reply. Society and the public have a right to expect high standards of performance, and intervention can be justified to secure the public good. Journalists and media professionals should be accountable to society as well as to employers and the market. 
Early followers of the theory believed that mass media should contribute to societal improvement. SRT has been widely recognised by media practitioners and scholars since the Commission on Freedom of the Press in 1947 as a theory that should operate with the concern of the public good. As noted by Hyun et al. (2016), the Committee on a Free and Responsible Press (1947) expressed the view that the press, within the purview of social responsibility theory, should provide a truthful, comprehensive, and intelligent account of the day's events in a context which gives them meaning; serve as a forum for the exchange of comment, and criticism and provide a forum for the exchange of comment and criticism. Furthermore, the press is charged to provide a representative picture of the constituent groups in society. Be responsible for the presentation and clarification of the goals and values of society and provide full access to the day's intelligence.

Based on the propositions of the social responsibility theory of the press, it may be argued that cartooning is a strategic editorial component to respond to social ills, to achieve the watchdog role of the press on various segments of the society, thereby positioning itself (the press) as being socially responsible to the public. In particular, political and corruption issues in Nigerian society are such that need intensive media attention in various dimensions, and cartooning could be regarded as an effective way of achieving this mandate.

\section{Method}

An in-depth interview, which is a qualitative research method, was employed by the researchers in this study. This method of inquiry involves conducting intensive individual interviews with a small number of respondents to explore their perspectives on a particular idea, programme, or situation. (Boyce \& Neale, 2016). In-depth interview study is not concerned with making generalisations to a larger population of interest and does not tend to rely on hypothesis testing, but rather it is more inductive in its process. As such, the aim of in-depth interviews is to create categories from the data and then to analyse relationships between categories while attending to how the live experience of research participants can be understood (Charmaz, 1990). In order to achieve the goal of this study, in-depth interviews were conducted with selected cartoonists to help throw more light and share their perspectives on the challenges they encounter as cartoonists in journalism practice in Nigeria. Therefore, six different cartoonists were interviewed across the national newspapers in Nigeria. The use of an in-depth research technique enabled the researchers to ask open-ended questions that elicited further depth of information from the selected cartoonists (Rubin \& Rubin, 2004). This approach (in-depth interview) is the most 
appropriate technique to probe into the challenges being encountered by newspaper cartoonists in Nigeria in general.

This study employed a purposive and snowball sampling techniques to select six (6) newspaper cartoonists, who granted interview sessions for this study. A purposive sampling is a non -probability sample that is selected based on characteristics of a population and the objective of the study. It is frequently used in social science when a researcher needs to reach a targeted sample quickly and when sample for proportionality is not the main concern. Certain criteria or characteristics are considered because of the nature of the study (Ashley, 2018). Consequently, the researchers selected six (6) newspaper cartoonists as interviewees across the national newspapers in Nigeria. The newspaper cartoonists interviewed for this research were selected based on a particular set of criteria, which include:

i. Expertise: the individual cartoonists selected and interviewed for this study had nothing less than 10years experience in the field of cartooning most especially in Nigeria newspapers.

ii. Full time or part time employment: All the cartoonists interviewed were officially employed by any one of the national newspaper organisations in Nigeria as a full time or part time staff.

iii. Retired cartoonists: These are professionals who are already retired from the job due to some reasons. They are regarded as important in this study because they were able to share their past experience. Their experience is also used to strengthen the baseline of the literature review.

The newspapers within which the cartoonists were selected include: The Vanguard, Nigerian Tribune, The Punch, New Telegraph, The Sun, and The Nation. The educational background of the 6 cartoonists showed that they are all graduates of Fine Arts and had their training through the in-house training system of each newspaper organization. These cartoonists have also attended several workshops and seminars in order to have optimal job performance.

\section{Discussion}

\section{The challenges involved in newspaper cartooning in Nigeria}

Findings from the interviews conducted shows that cartooning, as an art, is more of a talent than a learning skill among newspaper cartoonists in Nigeria. The cartoonists interviewed revealed the various challenges they face while carrying out their duties in the environment which they operate (Nigeria). According to all cartoonists interviewed in this study, the most common challenge experienced is the proprietorial influence. The New Telegraph cartoonist, (Personal Communication, July 4, 2018) notes that: 
the challenges we face start from the house, when you sketch a cartoon and your boss tells you this cartoon cannot go because this person is a friend to the organization and might not place advert again which is what keeps the company going. And of course, to keep your job we desist knowing fully well that 'he who pays the piper dictates the tune.

The Nation cartoonist (Personal communication, July 16, 2018), supports this view stating that, "in the media universally, there are proprietorial interests. One needs to protect his or her job by complying to that general maxim that "he who pays the piper dictates the tune." The Nigerian Tribune cartoonist took another shade, stating that:

The effort of the cartoonist is fruitless and the profession is life threatening and unsecured. The challenges of threats and insecurity, happened when subjects of the cartoons are aggrieved by their being subjected to satire. Also, the seeming futility of the efforts of cartoonists as seen in the increase in the level of malfeasance in the Nigerian nation. It appears Nigerians have grown thick skins and are no longer disturbed by the punches and messages of cartoons. Despite the avalanche of cartoons, evil and corrupt practices still prevail.

Furthermore, from the cartoonists interviewed, it was revealed that most of them are not well remunerated and this has been a major challenge to them. Accordingly, they feel they are worth more than their take-home pay. For instance, The Nigerian Tribune cartoonist, (Personal Communication July $11,2018)$, notes that 'the challenges of inadequate remuneration, poverty and economic insecurity have bedevilled the profession. The Nation cartoonist, (Personal Communication, July 16, 2018), supports this view, stating that, "cartooning in Nigeria newspapers is not rewarding because management of the media houses don't reward cartoonists the way they reward other journalists. The Sun cartoonist also corroborates this view that "cartoonists are not well remunerated, which has caused some of us to be out of job. In my organisation, we are just two cartoonists and I do not believe generations to come want to become a newspaper cartoonist" (The Sun cartoonist, Personal Communication, June 25, 2018). Supporting this view is the Nigerian Tribune cartoonist (Personal Communication July 11, 2018), who notes that 'the challenges of inadequate remuneration, poverty and economic insecurity make cartoonists themselves sad despite the fact that they make most people happy. The New Telegraph cartoonist, (Personal Communication July 4, 2018) states that "artists or cartoonists are not treated well as most organisations prefer to pay a reporter higher than a cartoonist." The same cartoonist laments further that, “in actual fact, we are all educated, and I can do a reporter's job but they cannot do mine because it is a 
gift. Media organisations should begin to treat us equally; it is an issue that has been lingering for years, we know and we are addressing it gradually."

In addition, The Nations cartoonist, (Personal Communication, July 16, 2018), asserts that:

Though cartoonists have columns or space dedicated to their jobs in the daily newspapers they are not entirely accepted as journalists. This is because no cartoonist has ever been elevated to the position of an editor of a newspaper. Some newspaper editors even regard cartoons as fillers to substitute for empty spaces, which indicates that newspaper organisations consider cartoonists to be less than reporters in professional status, showing them very little respect in many cases.

Conversely, the opinion of The Vanguard cartoonist differs from The Nation cartoonist in regards to remuneration. The Vanguard cartoonist states that "you have to be good as a cartoonist, you must show interest in the world around you because you might be tasked to sketch something or caricature something from anything around you" (The Vanguard cartoonist, Personal Communication June 28, 2018). The cartoonist states further that “on the issue of low remuneration, I don't have such an experience as my organisation has been paying me well and maybe that is why I am still here. Furthermore, the same cartoonist states that he is not accorded low respect among the reporters or journalists in his organisation. Similar to this is the opinion of The New Telegraph cartoonist, (Personal Communication July 4, 2018) who argues that:

It is true some organisations do not pay cartoonists well but in my own experience it has been a different case. You cannot accord me low for the worth of my efforts and creativity because cartooning is a deep concept that calls for creativity. I give my competence to any company that appreciates my worth and has not been disappointed ever since.

\section{Cartooning political and corruption stories in Nigeria and its attendant challenges}

Given the role of the media, their influence, and their agenda-setting role, the use of cartoons is essential in achieving these functions in society. This aligns with the opinion of the Nigerian Tribune cartoonist. According to this cartoonist, "editorial cartoon published in any newspaper organisation becomes a public discussion, especially in the digital world which we now operate." Furthermore, the cartoonist notes that "on this note, considering how corruption has eaten deep into the bone marrow of Nigeria and how our so-called leaders have ruined the economic system of the country, they cannot but be humorously criticised by cartoonists" (Nigerian Tribune cartoonist, Personal Communication, July 11, 2018). This same cartoonist also states that 'to a very great extent, politics and corruption are two 
major issues that have tugged at the very fabric of existence of the Nigerian nation and consequently have been given their fair share of attention. Corruption has been given different unflattering imageries as a horned evil while politics and politicians have forever remained at the receiving end of cartoonists barbs" (Nigerian Tribune cartoonist, Personal Communication, July 11, 2018). Similarly, The Nation cartoonist (Personal communication, July 16, 2018), confirms that they understand the nature of editorial cartoon and as such, they don't compromise political stories that are of public concern. In the words of the cartoonist,

Editorial cartoon is about opinion. This is the main reason why it mostly appears on Opinion and Editorial (Op-Ed) page of a newspaper. Opinions are diverse and subject to the nuances of the creator. So we need to focus special attention on corruption and politics because these two themes have always been a major part of the editorial content of most newspapers in Nigeria. I think my opinions and that of my colleagues should always be critical of the power that be. Again, the most important thing is that it must be revealing. It must shed more lights on issues. (The Nation cartoonist, Personal communication, July $16,2018)$

The Nation cartoonist notes that politics and corruption are very touchy topics for cartoons. Cartoonists must be mindful of internal interests while drawing political cartoons so as not go against the proprietorial interests. People accused of corruption at times threaten legal actions against newspapers. This is one of the challenges we often face and this makes cartoonists to be very careful before drawing cartoons on corruption issues. All the six cartoonists interviewed lamented how this has been a major setback for the growth of punchy editorial cartooning. The Sun cartoonist (Personal Communication, June 25, 2018) emphasises that, "imagine sketching one beautiful and radical story about a politician and unknowing to me, he is a friend to the company's chairman. I got a feedback at the point of gatekeeping that the story cannot fly because the person in question is a friend to the organisation." This cartoonist concludes that this kind of gameplay can be annoying and can kill creativity. The New Telegraph cartoonist, (Personal Communication, July 4, 2018) states further that the former chairman of The Punch newspaper, lost a political appointment on the basis of what The Punch sketched some time ago criticising Obasanjo while he (New Telegraph cartoonist) was still a staff of The Punch newspaper.

The Sun cartoonist (Personal Communication, June 25, 2018), states that "the main themes we draw in our cartoons are politics and corruption especially now that we are in a democratic rule. In most cases, we discuss politics because it affects all aspects of our life. Nigerian politics is structured in such 
a way that it breeds corruption. Therefore, politics and corruption dominate our concepts, and of course, they pose many challenges to us in the field." As noted by the cartoonists interviewed, some of these challenges include threat to life, insecurity, fear of job loss, family pressure, blacklist and castigation from government quarters, and influence from proprietors and superior officers. According to The Nation cartoonist (Personal communication, July 16, 2018), "we are seriously challenged given the fact that most of the Nigerian newspapers are owned by politicians or those who are close associates to the corridor of power. So it is a tall order for us cartooning politics and corruption." This cartoonist concludes that cartooning politics and corruption, especially in the government, means rocking the boat with your boss or the powers that be.

The experience of the Nigerian Tribune cartoonist shows that 15 out of his 20 cartoons are likely to be based or depict images of corruption and political anomalies in Nigeria. According to this cartoonist, "politics has affected our entire life in Nigeria and it has promoted corruption into the places of worship as religious leaders have been dragged into the unwholesome mud of corruption. Therefore, our feather and ink must be at work to expose these ills in our society" (Nigerian Tribune cartoonist, Personal Communication, July 11, 2018). In another perspective, the New Telegraph cartoonist holds that cartooning politics and corruption is a trade that can be likened to the genre of investigative journalism. It is different from cartooning general interest issues such as entertainment, sports, business, etc. In the words of the cartoonist, cartooning politics and corruption is like you are doing investigative journalism; which is clearly different from conventional reporting. Therefore, it goes with high sacrifice and determination because its price can be costly" (New Telegraph cartoonist, Personal Communication, July 4, 2018).

\section{Cartooning in Nigerian newspapers and motivational factors}

Despite the challenges faced by cartoonists in carrying out their professional duties, whether at the level of cartooning general issues or politics and corruption, it is interesting to note that while some cartoonists have quitted the trade of creativity, others stay and continue to give another flavor to journalism practice in the newspaper industry. Those who stay in the trade seem to have been principally motivated by personal interest and passion for the drawing profession. According to

Nigerian Tribune cartoonist, his motivation for the profession has sustained him and helped overcome whatever challenges come his way. In his words, 
Cartooning is more of an interest than a profession. The desire to have a voice in the way opinions are moulded towards the development of the Nigerian nation is my major driving spirit; and that is my passion. Cartooning is an important attention grabber and tool for socio-political engineering. And since many things are wrong in the Nigerian space with people using different platforms such as the legal profession, music, literary arts, advocacy, etc., I decided to use that of which I have talent to contribute to the development of Nigeria by offering alternative viewpoints to retrogressive policies and conducts through cartooning. Facing challenges in the course of carrying out my duties becomes normal because my passion for the profession has kept me going (Nigerian Tribune cartoonist, Personal Communication, July 11, 2018).

Similar to this view is the opinion of The Sun cartoonist (Personal Communication, June 25, 2018), who states that "the fact that my cartoon publication makes people laugh and becomes a topic of discussion motivates me to do more irrespective of the challenges I confront in carrying out my duties as a cartoonist. Furthermore, The Nation cartoonist, (Personal Communication, July 16, 2018), notes that, "cartooning is first a passion to me and then discover I can use my cartoons to highlight the plights of the common man. I hate injustice, maladministration and corruption orchestrated by people in government and as such, no amount of challenges can kill my passion and service to society". Interestingly, virtually all cartoonists interviewed contend that they are majorly motivated to do their job because of the perceived impact they make in the life of the reading public. This is evident from the feedback which make them fulfilled and want them to do more. This is further buttressed by The Nation cartoonist, (Personal Communication, July 16, 2018) interview, who states that

When you do editorial cartoons, sometimes it leads to trouble. We have, therefore, received threats severally through phone calls and short message service (SMS). This is because what one sees as a good meat is considered by others as poison. The reason being that corrupt elements are celebrated in the country by none other persons than the same commoners who are at the receiving end of the economic woes. But since our primary objective is to correct the ills in society with our cartoons, all we need to do is to apply wisdom by drawing cartoons that can positively influence the society. So when I influence my society positively, I am greatly motivated regardless of who is affected. We receive a lot of good feedback and we are thus motivated.

Also, The Sun cartoonist notes that

Despite the various challenges we encounter in our field, the only and major motivation we have thus far is our passion for the job and the recognition accorded to us by some sections of society. We are not encouraged by our organisations considering the poor remuneration and poor condition of service that characterise journalism practice in 
Nigeria. But our driving spirit lies in our passion, love and interest in what we do, and of course, the volume of accolades we receive from members of our reading public" (The Sun cartoonist, Personal Communication, June 25, 2018).

In line with the overall philosophy of journalism itself, community service and public interest are the driving impetus that engenders passionate commitment and practice among newspaper cartoonists. This is the view of the New Telegraph cartoonist who avers that "our passion is based on the fact that we have an opportunity to serve our community and report issues through our drawings for public interest. This is the best we can render to our society and that is enough as motivation for us" (The Sun cartoonist, Personal Communication, June 25, 2018). Most of these cartoonists were convinced that it is not only money that makes people to be happy. "If you derive joy and fulfillment in whatever you are doing for living, the passion to do and not to quite will remain green. This is what sustain our commitment in the trade of cartooning in Nigeria despite all challenges" (The Sun cartoonist (Personal Communication, June $25,2018)$.

Similar to the findings of other previous studies, this current research has established that cartooning in newspapers is a creative art, a journalistic genre purposively and strategically used by its specialists and authors to play the watchdog role, surveillance and perhaps, the role of societal cleansing. This is in tandem with the thrust of the social responsibility theory which holds that the media should balance freedom with responsibilities which bring the media to stewardship account of the public with a duty to be vigilant on behalf of the citizens and fair to all The social responsibility theory was saddled with not just factual reporting but investigative reporting to produce relevant and trustworthy news (Hyun et. al., 2016). In doing this, cartoonists encounter various challenges, especially from the government and those in power. This is why it is postulated that, under social responsibility theory, the media are obliged to fulfill certain obligation to the public by setting high or professional standards of informativeness, truth, accuracy, objectivity, and balance (McQuail, 2010).

As found in this study, the role of societal cleaning, seems to be age-long and perhaps, epiphenomenal to the nature and practice of cartooning, especially editorial cartoons. This resonates with the studies of (Jimoh, 2010; Eko, 2010; Olaniyan, 2018). For instance, the current study found that due to the punchy and witty approach of editorial cartoons to expose the ills of political power holders in Nigeria, which is also described as "the right to offend because cartoons are deliberate graphics" (Eko \& Berkowitz 2009 cited in Eko, 2010, p. 70), cartoonists have suffered or experienced threats to life and insecurity. This is in tandem with what Eko (2010) find and describes as 'confrontations', which "can 
result in journalists experiencing censorship (both overt and covert), kidnappings, beatings, imprisonment, forced exile, death threats, forced exile and even murder" (Eko, 2010, p. 70). This same finding; age-long battle between editorial cartoonists and the power and capital in Nigeria, may further be described as a re-echo of the conclusion of Philip (2015). Philip (2015) asserts that political cartooning, which poses a lot of challenges to its authors and creators, reflect the society and historical period within which the cartoon is produced, and it is an expression of corrupt social conditions, often tells untold stories and may challenge people to seek positive change.

The challenges confronted by cartoonists within the organisational set up, ranging from proprietorial influence, poor remuneration to less recognition by editors, may be regarded as 'jeopardy from within'. This is because, overall, the larger society; power structure and power play, more often than not, are not favourable to cartoon journalists and the 'home-front' (their various organisations) which is supposed to be the safe haven for them also remains very hostile. This is a clear reflection of the concern expressed by Charlie Hebdos, a cartoonist, that, around the world, cartoonists have millions of fans, but very few or no defenders! The only saving grace, succour and motivation that drive and sustain most cartoon journalists are the passion, and public interest they serve. In essence, the fact that most of them are self-motivated and perhaps, recognised by various platforms in society through honours and awards, motivate and sustain the cartoonists in them as professionals.

\section{Conclusion}

Cartooning, especially editorial cartoons, has come to stay permanently in media practice and journalism industry. While it gives flavour to journalism practice, its strength lies in the fact that the nonliterate group stands a fair chance to be part of the conversation and the projected message. Newspaper cartoons are indeed powerful and influential communication in our society. The many crises that have ensued as a result of the messages projected in cartoons at one time or the other across many climes of the world learn credence to it. Hence, one may conclude that cartoons constitute an important medium for framing social issues, political discourse, and other societal conversation. It is axiomatic to establish that cartoons cannot be dismissed on the grounds of political absurdity and ideological insignificance. This is so concluded because cartoons reflect political and social issues deeply. It must also be noted that the discursive spatial limitations of cartoons and their visual mode of communication should not be regarded as deficient in performing analytical communication. Therefore, cartoons and cartoonists are powerful tools and professionals who have the skills and potential to shape conversations in society. 
Despite all the above strengths, cartoonists have had to cope with two levels of challenge, namely: micro and macro challenges. The micro challenges are the ones encounter within their organisations, including but not limited. to proprietor's influence, poor remuneration, lower estimation, and respect by editors and other superior officers in their organisations. Furthermore, macro challenges are the victimisation, threats, political scheming, kidnappings, beatings, imprisonment, forced exile, and death threats, from the government. This level of challenge is broadly underpinned as 'confrontations' between cartoonists and the governments (Eko, 2010). Therefore, it appears apropos to conclude that as long as cartoonists put the principle of public interest first in their trade and practice, there would be a perpetual battle between them and the government, the power holders, and other groups whose interests are being 'jeopardised' by cartoonists. Essentially, there should be a general change of orientation in the attitudes of, and policies from media organisation executives, media owners, and top-level officers to give a desirable attention, respect and due recognition to cartoonists in their organisations. Cartoonists need to enjoy strong support from within and their own zone considering the fact that the outside world and the corridor of power are not always favourable. The self-motivation strategy being adopted by cartoonist is potent but may get vitiated if not complemented by other supporting approaches from the organisations for whom they work.

\section{References}

Adekanmbi, A. E. (1997). Cartooning and Animation. B.A Thesis. Obafemi Awolowo University, 1997. Agberia, J. (1993). The Role of Cartoons in the Social-Cultural Development of Nigeria. USO: Nigerian Journal of Art, 3(1), 32-42.

Akande, O. (2002). A Semiotic Analysis of Political Cartoons: A case study of Nigeria, University of Oklahoma, Oklahoma.

Boyce, C., \& Neale, P. (2006). Conducting in-depth interviews: A guide for designing and conducting in-depth interviews for evaluation input. Watertown: Pathfinders.

Conners, J. L. (2005). Visual representations of the 2004 presidential campaign: Political cartoons and popular culture references. American Behavioral Scientist, 49, 479-487.

DeSousa, M. A., \& Medhurst, M. J. (1980). Political cartoons and American culture: Significant symbols of campaign." Studies in Visual Communication, 8: 84-97.

Eko, L. (2010). The Art of Criticism: How African Cartoons Discursively Constructed African Media Realities in the Post-Cold War Era, Critical African Studies, 2:4, 65-91, DOI: 10.1080/20407211.2010.10530758 
Elkins, J. (2003). Visual studies: A skeptical Introduction: Psychology Press.

Everette, D. E. (1974). The Regeneration of Political Cartooning. Journalism Quarterly, 51, 664-669.

Feinberg, L. (1967). Introduction to satire: Iowa State University Press.

Feldman, O. (1995). Political reality and editorial cartoons in Japan: how the national dailies illustrate the Japanese Prime Minister. Journalism Quarterly, 72, 571-571.

Hyun, E., Yang, D., Jung, H., \& Hong, K. (2016). Women on Boards and Corporate Social Responsibility. Sustainability, 8(300), 1-26.

Jimoh, G. A. (2010). The role of editorial cartoons in the democratisation process in Nigeria: A study of selected works of three Nigerian cartoonists. Unpublished Master's dissertation. University of Lagos, Nigeria.

McQuail, D. (2010). McQuail's mass communication theory. Los Angeles, Calif: SAGE.

Olaniyan, T. (2018). Taking African Cartoons Seriously: Politics, Satire, and Culture. Michigan State University Press

Philip, A. O. (2015). Cartooning Contemporary Sub-Saharan African Experiences: A New Perspective. Review of Arts and Humanities, Vol. 4(1), 60-71.

Townsend, K. J., McDonald, P., \& Esders, L. (2008). How Political, satirical cartoons illustrate Australia's Work Choices debate. Australian Review of Public Affairs, 9(1), 1-26.

Robinson, J. (1981). The 1970s, best political cartoons of the decade: McGraw-Hill Companies. Rubin, I. S., \& Rubin, H. J. (2004). Qualitative Interviewing: The Art of Hearing Data (2nd ed.). Vinson, J. C. (1967). Thomas Nast: Political Cartoonist. Athens: CA: University of Georgia. 